\title{
Daubert's naïve realist challenge to Husserl
}

\section{(Penultimate draft. Forthcoming in Grazer philosophische Studien.)}

\author{
Matt E. M. Bower \\ Texas State University \\ membower@gmail.com
}

\begin{abstract}
Despite extensive discussion of naïve realism in the wider philosophical literature, those influenced by the phenomenological movement who work in the philosophy of perception have hardly weighed in on the matter. It is thus interesting to discover that Edmund Husserl's close philosophical interlocutor and friend, the early twentieth-century phenomenologist Johannes Daubert, held the naive realist view. I present Daubert's views on the fundamental nature of perceptual experience and show how they differ radically from those of Husserl's. I argue, in conclusion, that Daubert's views are superior to those of Husserl's specifically in the way that they deal with the phenomenon of perceptual constancy.
\end{abstract}

Keywords: Johannes Daubert; Edmund Husserl; perception; naïve realism; perceptual constancy

\section{Naive realism, the intentional view, and the phenomenological tradition}

The predominant view of perceptual experience, both within and without the phenomenological tradition, is that to perceive is a way of being intentionally directed toward something. That view is the prevailing view and it takes many forms. But it is not the only view. An alternative proposal, referred to as 'naïve realism' or as the 'relational view', has well-known antecedents in twentieth century Anglo-American philosophy (summarized in Travis and Kalderon 2013) and it has also attracted a growing number of adherents in recent years, particularly after its defense by Martin (2002), Campbell (2002), Travis (2004), and Brewer (2006). This is the view that I attribute to Johannes Daubert, an important but little-known figure at the very beginning of the phenomenological movement.

\subsection{The two core claims of naïve realism}

There are two core features of the naïve realist account of perceptual experience. ${ }^{1}$ First, naïve realists take perceptual experience to consist fundamentally in a relation between the perceiver and the perceived. Second, they take the phenomenal character of perceptual experience to be partly determined by the objects of perception. Whereas the first claim is ontological, the second is phenomenological. Concerning the first, the perceptual relation is supposed to be fundamental in the sense that the mind-world link that figures in perceptual experience has its own distinctive nature not to be explained by appeal to any deeper or more basic mental phenomena than the posited relation

\footnotetext{
1 Technically, what I will describe here is the naïve realist account of veridical perceptual experience only. Naïve realists almost universally accept a form of disjunctivism about perceptual experience on which to have a perceptual experience is either to veridically perceive or to hallucinate, where these two kinds of perceptual experience differ in their fundamental nature. For an account of what this entails and what might be said in favor of it, see Fish (2009) and Soteriou (2016). See Ali (2018) and Masrour (forthcoming) for a non-disjunctive version of naïve realism.
} 
and its properties. In that sense, the relation is "unanalyzable." It is sui generis or primitive, as something that cannot be said to consist of some other kind of mental phenomenon. For instance, it is not the case, on this view, that we stand in a conscious perceptual relation to perceived objects because the intentional or representational content of our mental states grounds such a relation. If that were so, perceptual experience might consist of a relation, but only by virtue of having other more fundamental constituents.

The perceptual relation, although unanalyzable in the way just mentioned, may still be described in terms of its own sui generis properties, the properties that make it the distinctive kind of mental phenomenon it is. Moreover, it may turn out to have non-relational features, provided these belong to perceptual experience by virtue of its relational features and not vice versa. Additionally, the perceptual relation is supposed to be a "real relation," one that holds between two really existing objects, namely, the perceiver and the perceived. It may be that relational predicates can pick out relations obtaining between presently existing objects and no longer existing ones (e.g., "is the son of') or mere possibilia. Not so for the perceptual relation, if naïve realism is correct. That implies that if you perceive some object, then necessarily that object exists. ${ }^{2}$

Naïve realists add to this a second claim, namely, that a perceptual experience's phenomenal character, the properties of the experience qua conscious experience, are determined by the perceptual relation. For them, the phenomenal character is either partly or wholly determined by its relational nature, so that the former is to be explained not by appeal to anything going on in your head, such as qualia, representational content, or adverbial modification, but rather by appeal to the world-involving relation you stand in to some particular entity. And by speaking of the relation determining the phenomenal character, the naïve realist understands that to mean not just that the relation, in abstraction from its relata, determines what an experience will be like, but rather that the relata, perceived object and perceiving subject, may also play a role in determining the experience's phenomenal character. The emphasis, in fact, is typically placed on the perceived object as shaping the contours of perceptual experience. That makes sense, given the recessive quality of perceptual experience, serving primarily to make the world around us consciously accessible and to a lesser extent, if at all, consciously manifesting properties of the subject or the experience itself independent of its relata.

Roughly, then, the experiential aspect of perceiving is supposed to be at least in part "inherited" from objects themselves. Or, more pithily, what the experience is like is a function of what the perceived object itself is like (Fish 2009; Allen 2016; but see Beck 2018). For instance, what

\footnotetext{
2 This might raise a concern about the plausibility of naïve realism. If perception consists of a real relation, what should we say about your visual experience of the stars in the night sky, some of which may have ceased to exist long ago? This is a genuine puzzle. While I cannot do it justice here, I offer the following tentative solution. See Moran (2018) for an alternative approach to the problem available to the naïve realist. I suggest that the naïve realist should class this as a kind of perceptual illusion, as James Genone (2014) conceives of it, that is, as misleading perception. When we view the night sky on a clear day, we view the light stars emit and not the stars themselves, i.e., the objects emitting that light. What we see in the sky thus belongs to an unusual class of visibilia, analogous in one respect to the perception of sound emitted from a distant object or a smell whose source may no longer be present, and in another respect to nonstandard visibilia like rainbows and encompassing mists. The luminous presences we see in the sky do not obviously look like their distal causes. It is a scientific discovery only partly based on that experience that there are such things as extremely distant astronomical objects that ultimately produce the luminous entities we see in the sky. Yet, knowing that the source of luminance is such an object, and either not reflecting on the relation between source and emittance or lacking a convenient way to describe it, we conveniently misdescribe our experience as being of distant astronomical objects.
} 
explains the redness as a constituent in the phenomenal character of my experience of a red apple is the redness of the apple itself.

\subsection{The intentional view: The centrality of representational content}

Let's turn now to the more mainstream alternative, which I will call the intentional view. By contrast to the first claim I attributed to naïve realists, it is one of the purported virtues of the intentional view to allow intentional directedness in cases where the intentional object does not exist or does not exist as it is intended. ${ }^{3}$ That is because intentional directedness is supposed to involve intentional content that determines what object(s) an intentional state is about.

This notion of intentional content is not totally foreign to phenomenology. Husserl is wary of the term's ambiguities and prefers "matter" instead of "content" to express the pertinent idea (Husserl 2001a, 112-113, 175), but nevertheless speaks in a generalizing way of "that peculiar side of an act's phenomenological content that not only determines that it grasps the object but also as what it grasps it" (Husserl 2001a, 121; Husserl's emphasis). He is also explicit that intentional directedness by way of content does not require real-time contact with the pertinent object, which remains external to or "transcends" the act and need not even exist (Husserl 2001a, 120). All of this applies, of course, to perceptual experience as well (Husserl 2001a, 104-105; 220-222). ${ }^{4}$ Even if it turned out that intentional content put the perceiver in a perceptual relation - a real relation - to the perceived, that would be a secondary matter hinging on more fundamental facts about the perceiver or, in Husserl's terminology, about the perceptual "act."

Very roughly, then, according to naïve realism, perception is fundamentally relational in nature and according to the intentional view it is fundamentally a matter of bearing intentional content. ${ }^{5}$

\subsection{Motivating naïve realism}

Given that I will be arguing in this paper that Daubert is a naïve realist, it is worth touching on the merits of that view. The mere fact that Daubert propounds a form of naive realism may be uninteresting in itself, but if the view is a worthy contender in the current debate about the nature of perceptual experience, that gives us further reason to explore the ideas of its historical precursors.

So, why think that perceptual experience is fundamentally a relation that a perceiver stands in to what they perceive or that the perceptual relation determines what it is like to perceive? One reason ${ }^{6}$

\footnotetext{
${ }^{3}$ See Fish (2009) and Soteriou (2016) for further discussion. Both works include accounts of how naïve realists can respond to the claim that phenomena like illusory and hallucinatory experience undermine the naïve realist claim that perceptual experience is fundamentally and essentially relational.

4 There is less agreement among proponents of the intentional view than there is among naive realists about how to understand perception's phenomenal character. Nevertheless, they are all agreed in rejecting the naïve realist claim that its phenomenal character is constituted by its relation to the perceived.

5 There are certain views of perceptual experience that you might think strike a middle path between these two options, being both relational and intentional in the relevant senses. The view that the intentional contents of perceptual experience are Russellian contents (Speaks 2009) entails that perceptual states are world-involving and thus relational. Similarly for the idea that the contents of perceptual experiences are de re (McDowell 1994), a view that has been attributed to Husserl (A.D. Smith 2008; D. Smith and McIntyre 1982; but see Romano 2012; Staiti 2015). Notice, however, that on such views the content is what bears the relation. It doesn't follow that the experience, the phenomenal character, should be understood in relational terms, as naïve realists claim. See Schellenberg (2010) and especially Genone (2014) for further discussion along these lines.

${ }^{6}$ For more arguments in support of naïve realism, see Campbell (2002), Fish (2009), Brewer (2011), and Soteriou (2016).
} 
is that naïve realism may better account for the distinctively presentational character of perceptual experience than its competitors (Hellie 2007; Fish 2009). In thought, we have things in mind only virtually, in their absence, by re-presenting them. When you think of something, something else or perhaps nothing at all stands in for the object of thought. In perceptual experience, on the other hand, we seem to encounter them, to have them in our awareness and not stand-ins of any sort. William Fish contends that, whether deployed by the folk or by trained philosophers, "the relevant metaphor" - namely, that of encountering, but similarly for metaphors like grasping - "is intended to capture a relation" (Fish 2009, 21). We encounter them, moreover, in the here-and-now, in propria persona. If so, it would be natural to view perceptual experience not only as a relation, but also as a real relation with a presently existing object and not some past, future, merely possible, or non-existent object: objects unavailable for encountering.

On the intentional view, perceptual experience is at bottom a form of representation, the sort of mental state whose virtue is precisely to enable merely virtual cognizance of things in their absence. There is thus a tension in the idea that we represent things when we perceive and the manifestly presentational character of perception. The problem is exacerbated by the fact that, as Fish notes, an encounter such as what seems to transpire in perceptual experience is always with a particular (Fish 2009, 22-23). This does not sit well with the intentional view, which is arguably marked by an ineliminable generality. The representational content that on this view is essential to perceptual experience imbues perception with generality. Here is how Bill Brewer explains the point:

According to [the intentional view], perception — even perfectly veridical perception, whatever exactly this may be-does not consist in the simple presentation to a subject of various constituents of the physical world themselves. Instead, if offers a determinate specification of the general ways such constituents are represented as being in experience: ways which other such constituents [...] might equally correctly — that is, truly-be represented as being. (Brewer 2006, 174)

The "general ways" Brewer speaks of, i.e., how perceived things are characterized as being, are determined by the representational content of the experience. Some defenders of the intentional view themselves have conceded that, whatever its other virtues may be, rather than accommodating the presentation of particulars, the most plausible forms of their view erect either a "veil of abstracta" or a "veil of nothingness" between the perceiving subject and perceived objects (Kriegel 2011).

Naïve realism thus has, and the intentional view lacks, the attraction that it easily accommodates the presentational character of perceptual experience. Being presentational, perceptual experience appears to involve both a real relation and the presence of particulars to perceptual awareness. As Harold Langsam argues, the perceptual relation makes the presentational character of perceptual experience intelligible in a way that the intentional view cannot (Langsam 2016). That is, perceptual experience has the presentational character it does because it involves a real relation, just as the first core claim of the naïve realist, the ontological one, states. What about the second naïve realist claim, the phenomenological one? The point about perception's presentational character does double duty. The presentational character of a perceptual experience is, after all, part of its phenomenal character. It is in describing what it is like to perceive that we are inclined to report that in perception we encounter things. So, by making perceptual experience's presentational character intelligible, the idea that perception consists of a real relation at the same time makes the phenomenal character of perception intelligible. 


\subsection{Situating phenomenology in relation to the current debate}

The relational view is little discussed among those with phenomenological interests working in the philosophy of perception, a dearth of interest likely due to the fact that the phenomenologists most influential in the philosophy of perception adhere to the intentional view. Among them is not only Husserl but also Heidegger, who tells us that: "As perception, [experience] is intrinsically intentional, regardless of whether the perceived is in reality on hand or not" (Heidegger 1985, 3940/31). That is, to perceive is to be intentionally directed in a way that may or may not hit its target, the intentional object. Similarly, Merleau-Ponty ascribes a "sense" to perception (Merleau-Ponty 2002, 4) that, like intentional content, is susceptible to error with respect to particular "appearances" (Merleau-Ponty 2002, 346-347; Berendzen 2014, 278).

Only a very small number of philosophers with a footing in phenomenology who work on perception appear to endorse the relational view, and they seem to have arrived at it independently and not in response to historical antecedents or more recent defenses of the idea in Anglo-American philosophy (Smith 1984; Mulligan and Smith 1986; Romano 2011, 2012, 2015). It has also received some skeptical (Hopp 2011, 2014) or noncommittal (Overgaard 2013) discussion. It is worth noting that Barry Smith, Kevin Mulligan, and Claude Romano all claim that perception is at bottom relational, like the naïve realist, yet maintain at the same time that perception is intentional. Hopp (2014) also considers this possibility (without endorsing it). This would seemingly blur the line I have attempted to draw between the naive realist or relational view and the intentional view.

The difficulty of reconciling the simultaneously relational and intentional characterizations of perceptual experience is only apparent. Smith, Mulligan, and Romano all explicitly note that the intentionality they attribute to perception is sui generis. They thus adopt pluralism about intentionality, i.e., the idea that there is not one criterion or set of criteria for determining whether a mental state is intentional. Perception (and perhaps other kinds of mental phenomena as well) is intentional due to its relational character, ${ }^{7}$ whereas, say, beliefs are intentional due to their intentional content. What makes perception intentional is not what makes belief intentional and vice versa. The air of paradox thus clears. Nevertheless, because talk of intentionality in philosophy of perception is typically not as liberal as this pluralist approach, I will not characterize perceptual experience as intentional in order to avoid confusion.

There is no obvious reason why naïve realism should be unattractive to those of a phenomenological bent. The view might rule out any idealism, such as is standardly attributed to the later Husserl. It may also be possible that the two ideas can be harmonized. If a transcendental idealist like Kant coherently holds a form of naïve realism, as Anil Gomes has argued (Gomes 2014, 2016), then perhaps Husserl, also committed to a kind of transcendental idealism, can do so as well. But whether the two fit together or not matters little. Phenomenologists contemporary to Husserl and onward have for the most part disavowed Husserl's idealism (e.g., Ingarden 1975; Sartre 1960; Levinas 1998), and even among Husserlians few find that to be a point of enduring philosophical value. There

\footnotetext{
${ }^{7}$ Although the bare fact of being relational will not be what accounts for that intentionality. Some further facts are called for here that would explain what sets the "intentional relation" apart from other relations. I thank an anonymous reviewer for highlighting this point for me.
} 
is, moreover, no need to fear that with realism comes physicalist reductionism. Naïve realists tend to defend a commonsense realism, one that leaves intact, for instance, the idea that the perceptible color properties things seem to have really do belong to those things (Brewer 2011; Allen 2016).

Naïve realism even has a feature that should make it attractive in comparison to the intentional view, to the extent that many phenomenologists favor a non-representational account of perception (Preston 1994; Zahavi 1994; Wrathall 1998; Moran 1999; Blattner 1999; Dreyfus 2002; Lotz 2007; Szanto 2012; Moran 2013). Naïve realism offers a resolutely non-representational account of perception. The perceptual relation does not reduce to more basic elements such as sense data, mental images, (non)conceptual contents, or propositional contents. Proponents of the intentional view, on the other hand, are prone to identify intentional content with representational content. "Representation" is admittedly a loaded term. Whatever else it may call to mind, it is widely considered sufficient for perceptual experience to count as representational if it possesses accuracy conditions (Searle 1983; Siegel 2010, 2009; Schellenberg 2011).

That idea fits neatly with what I noted above about the views of Husserl, Heidegger, and Merleau-Ponty, who all link the intentionality of perception with its susceptibility to error. Canonical phenomenologists didn't tend to use the language of accuracy. But consider again Heidegger's remark: "As perception, [experience] is intrinsically intentional, regardless of whether the perceived is in reality on hand or not" (Heidegger 1985, 39-40/31). He means to say that you can perceive things as being thus-and-so before you when they are not. The denial of a real relation in perceptual experience and the implicit attribution of accuracy conditions to it make it natural to read these phenomenologists as representationalists avant la lettre. Representational content, a meaning inherent to perceptual experience, underlies both. That meaning determines what the experience is about without requiring that the object be as it is understood in that meaning, let alone that it exists in the first place. So, where we now speak of accuracy and representational content, prominent classical phenomenologists preferred the language of illusion (Husserl 2001b, \$8; Heidegger 1962, \$7) and meaning (Sinn) (Husserl 1982, \\$129-132; Heidegger 1962, \32). A consistently anti-representational view would have to eliminate that content, as naïve realism does.

It may come as a surprise that there is in fact a precedent within the phenomenological tradition for a naïve realist view of perception. If it is to be found anywhere, you would expect to find it held by one of the Munich phenomenologists who found inspiration in Husserl's Logical Investigations shortly after its publication in 1900/1901. Many of these phenomenologists are known for their realism in various philosophical matters and for their disagreement with Husserl's idealism as it emerged in Ideas I (Smith 1997). It is Johannes Daubert, a lesser known but nevertheless influential Munich phenomenologist, who I take to be a proponent, contra Husserl, of a version of naïve realism in matters of perception.

Daubert's nearly indiscernible influence on the post-Husserlian phenomenological movement, in contrast to his considerable importance among the Munich phenomenologists and Husserl, is a consequence of his failure to publish any of his writings, a fact that leads Reinhold Smid to liken Daubert to Socrates (Smid 1985, 288). He did not publish and, compounding his obscurity, only small fragments of his writings have thus far been posthumously published (Smid 1984; Daubert 2002, 2004), making the bulk of his work virtually inaccessible. In what follows, I therefore rely heavily on quotations of Daubert contained in work by more recent scholars, and by Karl Schuhmann and 
Reinhold Smid, in particular. ${ }^{8}$ The claims I make about Daubert's views therefore come with the qualification that they may rely on an unrepresentative sampling of Daubert's works. That qualification is offset by the fact that the remarks I rely on are for the most part unambiguous in their meaning and that they fit together neatly to form a coherent story about perceptual experience.

\section{Daubert's naïve realism}

\subsection{Daubert on the directness of perceptual experience}

Daubert and Husserl - and the whole of the phenomenological tradition, as far as I am aware - agree that in perception we experience the world directly. When we perceive, we are experientially in the presence of the very thing we perceive. Nothing consciously discernible in our perceptual experience stands in the way, except perhaps other perceived objects. That is, perception seems to present us with mind-transcendent things themselves and not mind-dependent or mind-bound counterparts.

Husserl expresses the point thus: "In perception the object seem[s] to achieve full-bodied presence, to be there in propria persona" (Husserl 2001a, 137). Various remarks of Daubert's effectively make the same point, but without using the Husserlian language of the "full-bodied presence" (Leibhaftigkeit) of things. Rather, he remarks that "through perception reality is more immediately accessible than in meaning or in representation" (Schuhmann and Smith 1985, 788) and that "immediate access to reality is not reached through judgments or positings" (Schuhmann and Smith 1985, 784). In keeping with that thought, Smid reports that in describing the object of perception "Daubert preferred to speak of the 'real object' instead of 'sensuous empirical object"' (Smid 1985, 278). That lexical choice betrays, I think, a commitment to the idea that what is given in experience is the object in its intrinsic nature. We do not experience objects dressed, as it were, in some experiential garb (e.g., Lockean sensations of secondary qualities, qualia). This is confirmed by his comment that "[h]yletic data," i.e., what we immediately encounter in experience, "are not real component parts of consciousness" (Schuhmann and Smith 1985, 775).

\subsection{Daubert on the transparency of experience}

Of greater importance for us here is Daubert's endorsement of the transparency of experience, an idea that is closely related to that of the directness of perception. Perceptual experience is transparent if, when you accurately report all that you are conscious of when you perceive - in other words all that goes into the phenomenal character of your experience - your characterization of the experience only references the perceived object and its properties and you identify nothing belonging intrinsically to the experience independently of its object. ${ }^{9}$ Directness concerns the object of perceptual experience, whereas transparency concerns its phenomenal character. In principle, more than just an experience's object can be thought of as figuring in its phenomenal character. You may

\footnotetext{
${ }^{8}$ More specifically, many of the quotations I make use of are of manuscript passages from Daubertiana A I 3, written in the very late 1920s and very early 1930s. For a listing of the contents of Daubert's manuscripts, the Daubertiana, see AveLallemant (1975), 128-135.

${ }^{9}$ I present this as a sufficient and not a necessary condition. Transparency should not be held hostage to our ability to report on our experience. However, given that our reports about the phenomenal character of experience are accurate, they reveal its nature to us.
} 
be aware in perceiving not only of a perceived object, but also of certain features of your perceptual experience itself. If so, your experience is both transparent and direct.

However, directness doesn't entail transparency. To see one reason why, note that according to a purely adverbial theory of perception, perceptual experience has no object (e.g., no sense data, relational counterpart, intentional referent, etc.), strictly speaking, but consists only of various sensory modifications of conscious awareness (Ducasse 1942). Now, there is no reason, in principle, why an impure or hybrid adverbial theory could not include both directness and an adverbial element. The idea has been combined with both naïve realist (Conduct 2008) and intentional (Gert 2006) accounts of perceptual experience that espouse directness. There is no contradiction between the two, because the adverbial content (in the broadest sense of "content") is not an object of experience. But if perceptual experience has adverbial content, it is not transparent, because the experience itself has intrinsic properties that have nothing in themselves to do with any object of perception.

In short, then, there are three options. You can reject directness and transparency, accept directness but reject transparency, or accept both directness and transparency. Daubert opts for the last position. The following claim appears to make just that point: "Nowhere does one come upon it in its pure form, but always as entangled with a stuff which does not originate in it" (Schuhmann and Smith 1985, 776). Examining your experience reveals nothing of your experience itself as something above and beyond what it is that you are presented with in your experience. If that talk of entanglement makes room for uncertainty, further remarks leave little room for doubt. For instance, he writes: "that in which reality shows itself is nothing existing by itself, but only a function" Daubert's term of art for mental states - "directed towards reality" (Schuhmann and Smith 1985, 769). Or, even more pithily, "to have experiences is not yet to know that one has them" (Schuhmann 1989, 56).

In calling perceptual experience "nothing" he is stating that we can say nothing positively of an episode of perceptual experience except that it reveals an object with such and such characteristics. There is no subjective coloring whatsoever. Daubert is even more explicit on the point when he comments thus: "The seeing of a tree and the seeing of a house are, as seeings, not distinguished" (Schuhmann and Smith 1985, 779, n. 26). Or, what amounts to the same: "I do not know about mental processes involved in the act of seeing: I only know the objects toward which I turn" (Schuhmann and Smith 1985, 778). These remarks concern the proper criteria for individuating perceptual experiences. Given two distinct perceptual experiences, there is no fact about them as mind-bound or mind-dependent episodes that sets them apart from one another. The one and only thing, Daubert insists, that can be used to tell them apart is the object revealed in the experience and perceptually salient facts about that object.

He advises us to think of the nature of perceptual experience, that particular "function," as in a way similar to logical operators in propositions. If I know that some proposition $P$ is true, and I happen also to know that some other proposition $Q$ is true, the mere combination of both propositions in a single statement (" $P$ and $Q$ ") reveals nothing further about the world to me. "And" is not a referring expression and truth value it has derives entirely from the truth values of the conjuncts $P$ and $Q$. The experiential function, as it were, of "seeing" is, like the logical function, empty, inherently devoid of the value in question. Whereas logical operators derive a truth value from the propositions they link together, Daubert has us conceive of experiences as functions that derive their experiential value - their phenomenal character - from what they bring to awareness, i.e., "the 
objects toward which I turn," such as a tree or a house. So, "[t]he being of the object should be authoritative $[\ldots]$ for its make-up in perception" in a way analogous to how the conjuncts determine the truth value of the logical function "and" (Schuhmann and Smith 1985, 789).

\subsection{Daubert on perceptual experience as a relation}

So far, then, we've seen that Daubert endorses the ideas that perception is direct and that it is transparent. Although naive realists agree, and some even argue that the truth of such claims speaks in favor of naïve realism and against its competitors (Martin 2002; Kennedy 2009; Langsam 2016), there are prominent versions of the intentional view that are supposed to also accommodate the directness and transparency of perceptual experience (Tye 1995; Dretske 1995; Byrne 2001). So, we do not yet have sufficient reason to judge that Daubert is a naive realist. Yet, the way Schuhmann describes Daubert's view bears a striking resemblance to the position of the naive realist view when he says that on Daubert's view, "a perceptual act can only exist together with the thing perceived" (Schuhmann 1989, 55). That idea is not far from the naïve realist claim that perceiving an object, as a relation to that object, requires that the object exist.

The first piece of evidence I present in support of taking Daubert to be a naïve realist is indirect and consists of his explicit denial that perceptual experience is burdened with intentionality. In his own words: "This most original way of experiencing the world," that is, perceptual experience, "precedes every consciousness and all [conceptual] grasping" (Schuhmann and Smith 1985, 784). That statement may on its face not look like a denial that perception is intentional. Recall, though, that within the phenomenological tradition, following Husserl and Brentanto before him, the expression "consciousness" is interchangeable with intentionality. When they speak of conscious experience, they mean to highlight that experience insofar as it is conscious of something or other. Hence, "consciousness" doesn't have the sense it now has for many philosophers of referring to the subjective, qualitative character of "what it is like" to have experience or a certain kind of experience. And this makes the best sense of the remark I have just quoted from Daubert. He's not saying perception is unconscious or non-conscious, he's saying it lacks intentionality. That this is his view is supported by another remark of his: "The fundamental ${ }^{10}$ experience" - again, perceptual experience - "is not yet a "cognition-of" (Schuhmann and Smith $(1985,784)$.

Why might the denial that perception is intentional be recruited to argue in favor of naïve realism? Well, let's assume, as Daubert and most philosophers maintain (proponents of a purely adverbial theory notwithstanding), that perceptual experience is an affair that, at least when things go well, involves both mind and world. For all those who concur, it is a high-priority desideratum for any such theory to spell out just how it is that mind and world come together in perception. As far as I am aware, there are only two fundamentally distinct options, and these correspond to the accounts given by those who adhere to the naïve realist view and the intentional view. So, given that the intentional view is off the table for Daubert, it would follow that we're simply stuck with naïve realism.

\footnotetext{
10 The descriptor "fundamental" raises questions about just what Daubert is referring to in this remark. I take him to mean the most fundamental experience of reality. The implication is that he doesn't mean for what he says about perception to generalize over all forms of having reality in mind. This is a plausible interpretation, given that he acknowledges that there are other ways that we make cognitive contact with reality, i.e., in making judgments, that not only differ from perceptual experience, but that depend on the latter (Schuhmann 1989, 57-58; Schuhmann and Smith 1987, 366).
} 
Fortunately, in addition to that indirect reason for thinking of Daubert as a naive realist, there is also direct reason for doing so. Several remarks of Daubert's entail a relational view à la naïve realism. He writes: "If for fundamental reasons the real object remains outside consciousness, Husserl's idealism will eventually retain its right, or rather, it will become plausible, for there will be no argument left for the realist case" (Schuhmann and Smith, 1985, 773). Let's set aside the significance of this as a claim about idealism. What is plainly implied here is that, as Daubert sees things, the only acceptable view of perceptual experience is one that includes the perceived, the really existing, mind-independent object, within consciousness, rather than as its intentional target lying on the far side of the experience itself. This is just what the naïve realist maintains. The perceived object is a "part" of your experience, in the relevant sense, if it is a perceptual relatum, something brought into the perceiver's experiential purview by becoming the other term of a relation of perceptual apprehension.

That this is how we should understand Daubert's comment is corroborated by other things he says. Recall, as background, that Husserl attributes sense data ("hyletic data") to perceptual experience as mind-dependent and mind-bound phenomena and that he holds that we experience (erfahren) objects by virtue of experiencing (erleben) sense data (more on the two senses of "experience" shortly). Daubert responds to that view by claiming, first, that "in truth I never have such a criterion as to what belongs to consciousness, and what belongs to the conscious object" (Smid 1985, 276). He means to undermine Husserl's idea that you experience (erleben) something in a sense lying between yourself and the object you experience (erfahren) (Husserl 2001a, 112-115; Husserl 1982, 180-183/213216). ${ }^{11}$ There is no "criterion" for telling such a pairing of phenomena apart. And - as you would expect from an advocate of the transparency of perception - he doesn't infer from that point either that we should remain agnostic or that we should suppose that what we experience are subjective entities such as sense data as Husserl conceives of them. Perception, for Daubert, is "a multifarious encounter with what is real" (Schuhmann and Smith 1985, 781).

Continuing with the theme of sense data, he states that "Hyletic data are not real component parts of consciousness, because consciousness as a whole is nothing real" (Schuhmann and Smith 1985, 775). As we will see, this is not a denial of the thesis that sense data, when properly understood, are parts of consciousness in the sense that the naïve realist says they are (i.e., as terms of the perceptual relation). Daubert means, rather, that consciousness is not a triadic affair, with perceiver, sense datum (let alone intentional content), and object all lining up just right to bring about perceptual experience. It is a dyadic one, involving only the perceiver and the perceived itself. The relation that brings them together ("consciousness") is "nothing real" because it is a relation, something of a different ontological kind from things and their (monadic) properties (i.e., what is "real," of the order of the res). Daubert is willing to use the language of sense data, but, contrary to Husserl, he takes them to exist "in the transcendent sphere of objects" (Schuhmann and Smith 1985, 776).

As with naïve realism, then, the perceived object itself is a part of perceptual experience. To see why, let's reflect a little more closely on the move Daubert has made concerning sense data. Husserl admitted them as conduits, with the help of perceptual ("noetic," for Husserl) apprehension, for the intentional objects of perception. Daubert has eliminated the intentional object qua referent

\footnotetext{
${ }^{11}$ When citing translations of Husserl's works that include the pagination of the original German pagination in the margins, I will provide the page numbers of the German text first and then those of the English translation.
} 
of intentional content and along with it sense data as mind-bound and mind-dependent ("reelp" in Husserl's vernacular) entities. He keeps the perceived object as part of the experience, but models our access to it after the Husserlian conception of how sense data are experienced. Sense data, for Husserl, are not intentional objects. We experience them, but in a way that differs in basic respects from how we experience mind-transcendent objects. This is marked by Husserl's terminology, as I have noted parenthetically: We experience (erleben) sense data and experience (erfabren) (intentional) objects.

The terminological nuance is meant to signal that we're acquainted with sense data in a manner distinct from but far more intimate than our experience of objects via intentional content. Sense data are "really inherent" (Husserl's reell) parts of our experience in a way that objects are not. So, if on Daubert's scheme sense data are kept, but are identified with mind-transcendent and mindindependent entities, they remain experienced (erleben) in a non-intentional mode. We are acquainted with them in such a way that they are part of our experience. Daubert, like Husserl, exploits technical terminology to indicate the peculiarity of our acquaintance with sense data, dubbing it "Innesein" (Schuhmann and Smith 1985 784; Schuhmann 1989, 51). For Husserl, acquaintance with sense data is coupled with perceptual apprehension. For Daubert, on the other hand, we may apprehend the perceived and adopt intentional attitudes toward it (Schuhmann 1989, 57-58), but perceptual experience by itself is just sheer acquaintance with things or Innesein. This is exactly the move made by the naïve realist in response to classic sense datum theories (Martin 2002; Brewer 2011; Campbell and Cassam 2016).

Additional support for a naïve realist reading of Daubert can be found in his comments about the role of the perceived object in perception. The intentional view need not give the object much of a role at all, since one can be intentionally directed toward the object regardless of whether the object is present. The object need only figure in the event of successful perception. The naïve realist view assigns the perceived object an indispensable role as part of the experience, i.e., as its relational counterpart. If we present the views in terms of phenomenal character, the contrast is even more striking. On intentional views, as discussed already, typically the content and perhaps some other mind-bound ingredient, such as qualia, give perception its phenomenal character. On relational views, it is the object that gives perception its phenomenal character. Daubert appears to side with the naïve realist on the issue of phenomenal character.

He claims, for instance, that "The being of the object should be authoritative [...] for its makeup in perception" (Schuhmann and Smith 1985, 789). If our task is to explain why things appear as they do in perceptual experience, Daubert's suggestion is to look to perceived objects themselves for answers. Their nature determines how they appear. The following remark can be taken in the same way: "It must be made crystal-clear that reality is not a character of perception but something which remains stable throughout perception and indeed belongs to the thing" (Schuhmann and Smith 1985, 788). The idea is that if perception makes reality experientially manifest to us, that is not due any intrinsic qualities of the perceiver or their experience by itself, but rather to those of reality itself. According to Schuhmann's depiction of Daubert's view, "The object's mode of existence determines the way in which it can be apprehended" (Schuhmann 1989, 55). Daubert also describes perceptual experience as that in which "I experience the autonomy with which [the real object] accepts one determination and rejects another" (Schuhmann and Smith 1985, 789). The comment emphasizes the receptivity of perception. You take in the fact of the banana being green, for instance, and it is not the 
case that its appearing that way is a result of how you, however automatically, construe things. This is evidently an idea that Daubert had landed on relatively early.

In a recently published lecture delivered in 1902, we learn that Daubert had similarly conceived of a "consciousness of an object's demand," the experience of an object's "demands, demands that are announced in my consciousness that the object is composed in one way and not another" (Daubert 2002, 347). Although this experience is "present in each judicative act" (349), nevertheless, the two cannot be equated. Rather, consciousness of the object's demand is characterized as a precondition for judgment (353). This idea of experiencing an object's demand is not explicated in any detail, yet the choice of words to capture it suggests, in line with his later thought, that how an object is consciously presented in such experience is to be explained by reference to the object and not facts about the subject. The examples he gives to illustrate this experience, it is worth noting, are simple perceptual experiences, such as one in which "I see before me a red object" (351).

Finally, let me add one last piece of evidence for thinking of Daubert as a naïve realist. For this one, we circle back around to the issue of intentionality that we began with. In this case, Daubert is reflecting on Husserl's account and trying to spell out what is fundamentally dissatisfying to him about it. He is concerned that experiential contact with reality rests on shaky grounds if we follow Husserl and conceive of the experiential ground level, perception, in intentional terms. That is because of the possibility of error, maybe even pervasive error, that comes along with intentionality. Intentional directedness, as we've observed more than once, is an aiming that can miss its mark. You can have an experience in which the perceived "is meant as a physical thing and as existing, but [w] here the physical reality and existence is not itself present" (Schuhmann and Smith 1985, 782).

Husserl not only grants the point but is insistent about it:

Obviously, [my] characterization is not to be understood in the sense that there would pertain to the essence of every perception as such the existence of the perceived Object, the existence of that which stands there in the mode of presence of the flesh. In that case, talk of a perception whose object did not exist would be countersensical; illusory perception would be unthinkable. (Husserl 1997, 15/12).

That comment follows a passage where Husserl's central characterization of perceptual intentionality is as a "relation," and so the comment is reads naturally as a qualifier meant to point out his broad conception of that "relation." But this view, Daubert notes, would "imply that consciousness is not a relation of any sort between the object and the subject" (Schuhmann and Smith 1985, 782; emphasis added). That is, there is no relation in the relevant sense, i.e., no real relation. And he apparently wants to affirm, by contrast, that in perception "consciousness is related to an object" (Schuhmann and Smith 1985, 782; emphasis added). So, Daubert sees his view as differing from Husserl's in exactly the way that I characterized the naïve realist's view as differing from the intentional view.

\section{Daubert's departure from Husserl's view}

Now I want to take stock of the ways that Daubert's view entails a departure from the Husserlian view of perceptual experience. I will explain why two central tenets of Daubert's view entail a nearly complete rejection of Husserl's account of perceptual experience. Those tenets are that, for Daubert, perceptual experience is not intentionality-laden, as it is for Husserl, and that it is wholly transparent, as it is not for Husserl. Along the way I will highlight the key phenomenal elements 
Husserl attributes to perceptual experience that go out the window if Daubert's naïve realist view turns out to be correct.

\subsection{A point of agreement: The directness of perceptual experience}

I have already pointed out that one issue about which both Husserl and Daubert appear to agree is that to perceive is to directly experience things. This is what Husserl tries to intimate with his talk of the "bodily presence" (Leibhaftigkeit) of the perceived. And, for Daubert, the directness of perception follows from the transparency of perceptual experience. That is, because whenever you faithfully report on your perceptual experience you inevitably end up describing the perceived object and its perceptible properties, it follows that it is just the object itself and its properties that you perceive. For both Husserl and Daubert, then, it would be a misdescription to attribute sense data, "mental paint," mental images, judgments, (non)conceptual contents, or (non)propositional contents to perceptual experience as themselves perceived intermediaries by means of which you indirectly make contact with the perceived. I will return to the issue of directness shortly to highlight an important difference in how Daubert and Husserl conceive of the directness of perception, but for now I only want to emphasize perhaps one substantive point of overlap between Husserl's view and Daubert's view of perceptual experience.

\subsection{A first divergence: Perceptual intentionality}

A deep and fundamental chasm lies between Husserl's view and Daubert's due to their divergence about whether perceptual experience involves intentional directedness. Husserl thinks it does. He speaks of the perceived as an "intentional object" and attributes "perceiving intentionality" to perceptual experience (Husserl 1977, 188/141; Husserl 1997, 14-15/11-12). Daubert disagrees. For him, we've seen, "The fundamental ${ }^{12}$ experience [of reality - MB] is not yet a "cognition-of" (Schuhmann and Smith 1985, 782, 784). It immediately follows that the rather complicated suite of intentional features that Husserl ascribes to perceptual experience will have no place in Daubert's account. Daubert will ascribe neither noetic nor noematic content (in the broadest sense of that term) to perceptual experience. That is, he will deny that perceiving involves "apprehension" (Auffassung) or sense data, on the noetic side, and will likewise deny that it involves a "matter" or "noematic sense" ( $\operatorname{Sinn}$ ) that determines how the object is perceived and is in some sense distinct from the perceived object (Schuhmann and Smith 1985, 786; Drummond 2008, 57-58, 144). The role of all of these, in Husserl's account, is to explicate the nature of intentional directedness in perceptual experience. Since, for Daubert, perceptual experience lacks intentional directedness, he has no need to posit such components of perceptual experience.

As I have noted, Daubert is concerned that intentionality will not truly establish contact with the perceived (Smith and Schuhmann 1985, 772, 788; Schuhmann 1989, 58). Its shortcoming stems from its inherent connection with the possibility for misapprehension and error. A relational view, like naïve realism, on the other hand, circumvents the difficulty, and that is why Daubert espouses a form of naïve realism. It is true, though, that naïve realism then faces a different challenge, namely, that of explaining illusion and hallucination as phenomena that appear to be perceptual in nature. Husserl himself, in the passage I quoted earlier, notes the difficulty: "In that case, talk of a perception

\footnotetext{
${ }^{12}$ See note 7 above.
} 
whose object did not exist would be countersensical; illusory perception would be unthinkable. (Husserl 1997, 15/12).

The most common reply is to say that illusions are veridical but misleading perceptual experiences and that hallucinations differ fundamentally in kind from veridical perceptual experiences (Martin 2004; Fish 2009; Brewer 2011; Soteriou 2016; but see Ali 2017). The view that hallucination and veridical perceptual experience differ in their fundamental nature is called disjunctivism, and the alternative, that hallucinations and veridical perceptual experiences have a common nature, is called the common factor view. That may or may not count as a relative disadvantage for Daubert's view in comparison to Husserl's. It is been argued that Husserl accepts the common factor view (and that this is problematic) (Romano 2012), that he is a disjunctivist (A. D. Smith 2008), and that he opts for some third option besides disjunctivism and the common factor view (Staiti 2015). So, in this dialectical context, given the apparent ambiguity of Husserl's position and the plethora of attempts to formulate a satisfactory naïve realist account of illusion and hallucination, it is not necessarily problematic for the naïve realist to leave no room for perceptual error.

\subsection{A second divergence: Perceptual transparency and lived experience}

Daubert's acceptance of the transparency of perceptual experience is yet another fundamental divergence from Husserl's view. Let's return for a moment to the issue of the directness of perception. Husserl claims that the only thing we experience (erfahren) in perceiving are mind-transcendent objects, and that they are given immediately with bodily presence (Leibhaftigkeit) without other perceived items given in experience (Erfahrung), interposed between the perceiver and perceived. There is a wrinkle, though, in his story, an additional feature that requires Husserl to deny the transparency of perceptual experience.

I have in mind his reference to how we experience (erfahren) mind-transcendent objects only due to the experience of mind-bound experiential phenomena, what Husserl calls "lived experience" (Erlebnis), such as the elements of apprehension and sense data that figure in perceptual experiences and that are supposed to go into the phenomenal makeup of that experience. Husserl writes:

Every intentional lived experience taken in pure immanence has its real [reele] part, as, e.g., the hyletic data included in it, tone-data, etc., which are really included in it. But also the character of the adumbration of something objective is a real part, a part of the immanently concrete lived experience [...]. (Husserl 1977, 172/132; emphasis added)

We experience (erleben) such things even though they are not given as intentional objects. Whereas intentional directedness is susceptible to error, error is impossible, Husserl says, when it comes to acquaintance with lived experience (Erlebnis) (Husserl 2001a, 102-105, 342-346; Husserl 1982, 65/75, 74-75/86-88). Further, whereas mind-transcendent objects are, for Husserl, necessarily experienceable but not necessarily experienced, he maintains that lived experience is not merely necessarily experience-able, it is necessarily experienced (Husserl 1983, 83-85/98-100).

Yet, if Daubert is correct that in faithfully reporting on what you perceive you describe nothing but the object perceived and its perceptible properties, then you will certainly not make reference to any such lived experience. As he claims, "The seeing of a tree and the seeing of a house, as seeings, not distinguished" (Schuhmann and Smith 1985, 779, n. 26). That is, the two do not differ by having 
different lived experiences of apprehension and sensory contents. They differ simply because they present different objects.

This quotation is also worth repeating here: "I do not know about mental processes involved in the act of seeing: I only know the objects toward which I turn" (Schuhmann and Smith 1985, 778; emphasis added). "Mental process" here is a translation of the German Erlebnis, the term I have been using parenthetically as equivalent with the English term of art "lived experience" (Frechette 2013, 667, n 21). Now, that word is not one used exclusively by Husserl, but, as Guillaume Frechette understands Daubert's remark, it is the peculiar Husserlian usage that Daubert has in mind. Daubert intends here to refer to experience not in a maximally broad sense, but experience in the narrower sense of purportedly introspectively available, mind-bound proper parts of the stream of consciousness. According to Husserl, such experiences exist and function to "constitute" mindtranscendent objects, i.e., they enable intentional directedness toward and conscious awareness of the latter. Daubert's remark is part and parcel of his rejection of the idiosyncratic Husserlian notion of constitution as, in Frechette’s words, “a plain fiction” (Frechette 2013, 667).

\section{The superiority of Daubert's view over Husserl's: The puzzle of perceptual constancy}

At this point we run into an apparent impasse. Husserl reports that it is part of the phenomenal character of perceiving that we have certain lived experiences. Daubert reports finding no such lived experiences and nothing but sheer experiential exposure to the world. Troublingly, the standoff might recall the intractable dispute that is supposed to have led to the downfall of the introspection-driven psychology practiced (e.g., by Wilhelm Wundt and Edward Titchener) in certain quarters in the late $19^{\text {th }}$ and early $20^{\text {th }}$ centuries. Here, however, there is a principled way of settling the dispute. Both sides present reasoning in favor of their preferred take on the issue. I will present their reasoning and argue that Daubert's is more satisfactory than Husserl's and even eliminates the motivation Husserl has for making appeal to lived experience in his account of perception.

Daubert's move is of a type that has gained wide currency within the phenomenological tradition. Sense data, you will recall, represent one form that lived experience can take. Let me quote Daubert on the matter of lived experience of sense data: "[T] he objective quality of red cannot be distinguished from the sensory content of red" (Smid 1985, 286). His point is that experience presents us with colors as properties of objects without any distinct, consciously discernible color sensations attending them. The point has been made by many others within the phenomenological tradition (Heidegger 1985, 47-49/37; Gurwitsch 2010, 41-42; Sartre 1956, 315-316; Merleau-Ponty 2002, 378; Levinas 1969, 135). Sense data comprise one broad class of lived experiences. Daubert's idea seems to be that the point about sense data generalizes to other purported kinds of lived experience, such as perceptual apprehension and noematic content. He takes the kind of move made in the critique of sense data and uses it to exert pressure on all manner of lived experience.

Compare the following remark with the one just quoted about sense data: "[ $]$ n truth I never have such a criterion as to what belongs to consciousness, and what belongs to the conscious object" (Smid 1985, 276). Just as there is no, let's say, phenomenal "purple" accompanying your perception of an object's being purple, so experience generally contains no phenomenal counterparts any aspect

of a perceived object. As our interest is in perceptual experience, the burden of proof lies on the shoulders of the advocate of lived experience to indicate where such a thing shows up in the phenomenal character of our experience (i.e., as something we are aware of simply by having that 
experience). Clearly, it is not the case that you can attend to lived experience in the way that you can attend to the dust, cracks, and other imperfections of an otherwise transparent window. But they must do some work in explaining the phenomenal character of experience. Daubert confesses that he can find no work for it to do. If lived experience is not phenomenally manifest and no phenomenological grounds can be given for positing it, we're better off without it.

\subsection{Husserl's appeal to lived experience to explain perceptual constancy}

Yet Husserl surely has reason for introducing lived experience. Indeed, he thinks there are phenomenological grounds for positing both lived experience of sense data and apprehension. We will focus on just this case to see how Daubert's and Husserl's views fare. Husserl appeals to the phenomenon of perceptual constancy in which objects or properties are experienced as identical despite alterations in how they appear due to changes in perceptual circumstances (Husserl 2001a, 103). In perceptual constancy, the perceived object in some sense both looks the same and doesn't. For instance, a coin's shape will vary in appearance as it is rotated. Its reflective qualities will alter their appearance in the process, or as lighting conditions vary. Drawing the coin close to your eyes, it will take up a great deal of your visual field, ${ }^{13}$ whereas it occupy hardly any visual field if you set it on a table on the far side of the room. By hypothesis, we're imagining a single coin perceived in these diverse conditions.

By Husserl's lights, the fact that the appearances vary means that the appearances are distinct from the appearing object (Husserl 1997, 37-45/31-39; Husserl 1977, 172/132; Husserl 2001b, 337/37-38). The mind-bound constitutive components of the appearance that matter the most in explaining what is going on here are sense data and perceptual apprehension. The sense data account for the varying appearances and the perceptual apprehension accounts for how, despite sensory variation, a single object is perceived. I qualify the apprehension as perceptual to indicate that, as Husserl conceives it, it is a proper part of the perceptual experience and exists only as part of an experience in which it is correlated with certain sense data. That sets it apart from judgment, which needn't be so correlated. On the other hand, judgment is, but perceptual apprehension (being "prepredicative") is not correlated to some proposition (Husserl 1973, 27-28).

Now, it remains true that sense data and perceptual apprehension do not show up in experience in the way that perceived objects themselves do. They become no more prominent upon reflection. We only take them into account as explanatory posits that are supposed to render intelligible the combination of experienced sameness and experienced variation. They are thought to explain the phenomenal character of our experience, but it is not obvious where they show up in that experience itself. Notice, too, how the phenomenal character of the experience ends up being explained almost entirely by appeal to subjective features, and ones that philosophically untutored perceivers fail to notice, rather than those of the perceived object.

\subsection{A Daubertian rejoinder to Husserl's account of perceptual constancy}

Husserl thus provides criteria for how to tell two seeings apart, as seeings, contra Daubert's assertion. Cases of perceptual constancy are supposed to require differentiating appearance from what appears. Two remarks of Daubert's indicate the sort of response that is available to him. First, he

\footnotetext{
${ }^{13}$ I will return to the issue of the visual field below, in Section 5.
} 
writes: "Things are not adumbrated in data of sensation, but always only in modes of appearance and in aspects" (Schuhmann and Smith 1985, 777). This remark suggests that, in keeping with how I have presented his view, Daubert will try to account for phenomenal differences, where they exist, in terms of the perceived objects themselves. The next remark is a bit more specific: "Objective appearance is bound e.g., to the laws of perspective" (Schuhmann and Smith 1985, 777).

Let's consider a very simple case. You are looking at a green banana sitting on a table across the room from you. You then walk towards it until it is now sitting immediately before you. All will agree that your visual experience altered in the time between the initial and final viewing of the banana. There is some sense in which your experience of the banana changed over time. Husserl offers both a way of understanding what the different appearances are - i.e., sense data - and how they are ultimately linked together - i.e., via apprehension - to present just the green banana. His response to the puzzle in perceptual constancy is predicated on an assumption that needs to be made explicit: That a change in how something looks with respect to its intrinsic properties reflects either a change in those properties or a subjective change in the experience itself. Without that assumption, there is no puzzle. For instance, if the banana is perceived at the same distance and otherwise positioned in the same way in relation to you, the perceiver, except that it has been moved to the left or to the right, it will appear differently, e.g., as situated nearer the edge of the table and more to your right than it previously was. The difference boils down to one in perceived relational properties, i.e., of location in egocentric space.

So, what is different about cases like the one just described and that of a banana being viewed at a distance and then up close? Here Husserl seems to entertain a thought similar to that of British empiricists like Berkeley who report that it "looks smaller" from a distance and "looks bigger" up close. It is unclear whether Husserl would - let alone should - agree with Berkeley's observation. But, in cases like this, he does hold that something changes in the appearance of size. Returning to the banana, maybe now that you are closer you notice where it is starting to yellow. You might also see it positioned differently with respect to yourself. The latter alterations in your experience could be taken as revealing the banana to change its color and shape. Puzzled, you might ask: How can the appearance of an intrinsic property change without the property appearing to change as well? Husserl posits lived experiences of various kinds to sort the puzzle out. One and the same intrinsic property can be presented by means of phenomenally distinct lived experiences.

Daubert's approach to the puzzle of perceptual constancy, we know, will have to appeal to the perceived itself. One and only one thing, the banana, is perceived, and it does not appear to change in any of its intrinsic properties. His best option for dealing with the puzzle is to reject the assumption that the pertinent changes in appearance reflect changes in the object's intrinsic properties (e.g., shape, color, size). There are at least three ways to do that. First, Daubert can deny that there is any change in how the intrinsic properties appear and chalk up the change in appearance to a correlated change in extrinsic, relational properties (as in Tye 2002). Second, he could allow that there is a change in how the intrinsic properties appear due to being presented with greater acuity or determinacy (as in Stazicker 2018). (Think of how, e.g., fog affects vision that way.) Third, he could allow that there is a change in how the intrinsic properties appear and explain the change by arguing that we only ever perceive stable intrinsic properties by virtue of perceiving fluctuating relational properties (as in Noë 2004). If any of these sorts of explanation for phenomenal change are tenable, then Husserl's puzzle 
disappears and with it so does one key motivation for introducing the lived experience of sense data and perceptual apprehension.

Let's begin with the phenomenal change from being distant to being near the perceived object. What happens, simply in virtue of that change, is that the object takes up more of your visual field. Imagine further that you are now holding the banana before you, level with your eyes. It is come to take up a significant portion of your field of view. When it is so close to you, it crowds out the potential visual competition. It doesn't look any bigger. It looks closer. You thus perceive it as altering in certain of its extrinsic spatial properties, namely, it is location with respect to you. And at least part of looking closer, for an item of constant size and shape, is filling out more of your visual field at the expense of other things it occludes, precisely because it does occlude them.

We also supposed that you might see it from a different angle and with color properties you didn't initially discern. For a response like Husserl's to the puzzle of perceptual constancy to be warranted in the latter case, you would have to experience a change in the banana's color. Do you? It is open to Daubert, I think, to urge that the initial viewing was incomplete or indeterminate with respect to color. You saw the banana as vaguely green. You can now pick out its color with greater determinacy and detail. It is indeed green, for the most part, with some yellow. You do not see its color changing, you see its color coming into greater clarity and detail. On this score, then, there is no change in intrinsic properties. All we can say is that you've had a better look at the banana's color, because some aspects of its color weren't initially experientially accessible.

Consider next the change of appearance attending relative change in position. Maybe you first saw its typical curved shape, but now hold it in front of yourself rotated so that the curve is not apparent. You did not see it change shape. Not in any respect. But there is a phenomenal change with respect to its shape. More of its shape comes into view, because you see some of the side that formerly wasn't facing you. And when the banana is turned to obscure its curvature, you also see less of its shape. You fail to see its curved shape, although you see other aspects of its shape, such as its length and cylindrical features. You might even still be able to make out its curvature in suitable lighting. If the banana is turned to only partially obscure the curvature, then again you see its curvature, but you see its curvature oriented differently, a change merely in its extrinsic spatial relation to you, the perceiver.

This is only a limited sampling, and similar examples could be multiplied. The examples suggest that closer attention to the way the object itself is presented may serves to dispel the mystery surrounding constancy phenomena and sap the explanatory motivation from Husserl's lived experience-positing resolution of it. The puzzle is only deeply puzzling in a way that motivates Husserl's view if the change in appearance is necessarily an appearance of change, and, moreover, change in the intrinsic properties of the perceived. That is because the experience is supposed to be of a single object or property that neither changes nor is perceived to change. The puzzle involves an alleged phenomenal conflict in how the object is experienced in its intrinsic properties. But I have offered in the spirit of Daubert's view what I think are good reasons for denying in certain instances either that there is an appearance of change at all or that there is no appearance of change in the intrinsic properties of the perceived.

Given that, there is no deep puzzle, because there is no phenomenal conflict. In cases of extrinsic change, there is nothing puzzling about a single item undergoing such changes while retaining 
its intrinsic properties. There is likewise no conflict when your experience of the item alters to reveal more or less of it or to reveal it in greater or lesser determinacy. The relevant phenomenal changes reflect changes not in the perceived object's intrinsic properties, but in its relation to the perceiver's surroundings and to you, the perceiver.

\subsection{Daubert and nä̈ve realist accounts of perceptual constancy}

Contemporary naïve realists offer resolutions of the puzzle of how to explain phenomena of perceptual constancy similar to the one just sketched drawing on relevant remarks of Daubert's. Some naïve realists have made similar points concerning phenomena of perceptual constancy as those I have made on Daubert's behalf above, namely, that changes in appearance may be explained by more or less of a thing or property appearing (Kalderon 2011), by its having properties that explain its constant appearance and other, distinct properties that explain its varying appearance (Allen 2009), or by changes in its relational properties (Genone 2014). Other naïve realists have altered the naïve realist position somewhat to provide a solution. Perceptual experience, they urge, is not simply a relation between perceiver and perceived. Matters are more complex. Rather than the two-place conception of the perceptual relation, many naïve realists adopt a three-place conception of it (Campbell 2009; Brewer 2011). The third term is the perceiver's perceptual point of view or standpoint. Perceptual experience is a matter of a perceiver being experientially related to an object from some point of view. Thus, alterations in experience correspond not only with alterations in what object you perceive, but also with your point of view on the perceived, so that an identical object or property may appear differently given suitable alterations in point of view.

In the limited manuscript evidence that is presently available, Daubert does not explicate his view along any of these lines. Nevertheless, I believe what he does say in his comments describing perceptually experienced "modes of appearance" and "aspects" of things as "objective" and governed by "laws of perspective" is at least consistent with some of the naïve realist views just described (Schuhmann and Smith 1985, 777).

Daubert apparently thinks of perceptual experience as consisting of a relation of conscious apprehension to the perceived object. At the same time, he seems to recognize the existence of phenomena of perceptual constancy, as talk of modes of appearance and aspects suggests. His mention of "laws of perspective" is surely meant to gesture toward the sort of explanation of phenomena of perceptual constancy he would offer as an alternative to Husserl's. Presumably, in calling laws of perspective objective he means to say that they are not mind-bound or mind-dependent, and that they belong to the same order as perceived objects and properties. These laws of perspective are somehow supposed to figure in our experience, so they must figure in the relation that constitutes the experience. One way to accommodate that would be, similar to Genone (2014), to think of the laws of perspective in terms of relational properties of the perceived. Another way, similar to Campbell (2009), would be to think of the laws of perspective as part of a third term in the perceptual relation, making up, at least in part, the subject's point of view.

\section{Conclusion}

Philosophers working on perception divide into those who accept the intentional view, the prevailing view, and those who accept naïve realism. Naïve realism, despite its lesser prominence, has 
nevertheless become a central topic of discussion within the philosophy of perception. It is time for phenomenologists and those informed by the phenomenological tradition working on problems in the philosophy of perception to face the challenge of naïe realism head on. To date, it has received hardly any attention from the phenomenologically-inclined. There is no good reason for this. True, naïve realism does contain ideas that are at odds with the more-or-less consensus view among phenomenologists that perceptual experience is intentionality-laden. But there is no reason to think that a phenomenologically-informed view of perception must adopt a version of the intentional view.

At the very beginning of the phenomenological movement, Daubert simultaneously embraced the philosophical style of Husserl's phenomenology (circa the Logical Investigations) and, on my reading, adopted a naïve realist view of perceptual experience. And, as I have argued, his account has some explanatory advantages over Husserl's. There is obviously more work to be done to elaborate Daubert's view in greater detail and compare it more broadly with other phenomenological and nonphenomenological accounts of perceptual experience. I hope that I have provided motivation for undertaking that work.

Let me indicate, in closing, a couple of further points that need addressing in future research on Daubert's philosophy of perception and relation to contemporary naïve realist approaches to the issue. The two issues I will now raise correspond to the two core claims of naïve realism as I presented it in Section 1. On the one hand, a positive account of the nature of the perceptual relation is needed. I have identified evidence for thinking that Daubert understands perceptual experience to consist in a real relation with the perceived object and explained what motivates him to take that position. That is a far cry from elaborating what all goes into that relation. According to some naïve realists, this should also be a priority for contemporary advocates of naïve realism (Kalderon 2018). There is therefore a prime opportunity for mutually-enlightening research by those interested in Daubert's thought and in naïve realism.

Further, research into Daubert's view of perceptual experience must address more precisely the connection between the relational character of perception and its phenomenal character. Naïve realists generally agree that perception's phenomenal character is at least partly determined by its relation to the perceived object. Yet there is significant disagreement about the degree to which phenomenal character is determined by or "inherited" from that relation to the perceived object (Christy 2018; French 2018). More austere versions of naïve realism explain phenomenal character as exhaustively determined by the perceived object, while less austere versions point to the subject of the experience and the relation itself as making a difference in phenomenal character. Whether greater or lesser austerity is called for in this regard depends significantly on how to understand transparency. More austere accounts will find that nothing but the perceived object and its properties enter into our conscious awareness in perceiving. Less austere accounts will allow that in perceiving there are aspects of our perceptual awareness that cannot be explained by appeal to corresponding aspects of the perceived object.

There is some reason to think Daubert would lean in the direction of a more austere view, given the strong position he takes on the issue of transparency. Let me reproduce a couple of pertinent remarks that might give that impression. Daubert writes: "The being of the object should be authoritative [...] for its make-up in perception" (Schuhmann and Smith 1985, 789) And this: "I do not know about mental processes involved in the act of seeing: I only know the objects toward which I turn" (Schuhmann and Smith 1985, 778). What these remarks tell us about Daubert is that he takes 
experience to be transparent in the sense that there are no subjective correlates of perceived objects and their properties that figure in the phenomenal character of perceptual experience. As I explained above (see Section 4), he had in mind specifically Husserl's notions of lived experience and constitution. In more contemporary terms, Daubert is denying the existence of introspectively accessible sense data, subjective qualia, or representational content as phenomenal constituents of conscious perceptual experience.

Yet, Daubert may not hold a maximally austere view of transparency. That is, if there are plausible candidate constituents of perception's phenomenal character that do not fit the description of what he has specifically ruled out and that can be accommodated in the naïve realist framework I take him to be working with. I raise this issue here only to indicate avenues for further exploration. To anticipate one direction that might take, accounting for the bounded or field-like character of perceptual experience (e.g., how objects are presented within a visual field) may require a less-thanperfectly-austere understanding of transparency. The boundaries of a token perceptual experience at a given point in time are not obviously explainable in terms of the objects of perception, as if, e.g., the limits of the field of vision corresponded to certain features or properties of the scene perceived.

Yet, some account of the boundedness of perceptual experience is needed. Consider, for instance, how earlier (Section 4) reference to the visual field was unavoidable in describing the experience of size constancy. And Daubert, albeit rather implicitly and tangentially, had some interest in the phenomenon, too, at least as it bears on the constraints that perceptual experience imposes on judgments about states of affairs lying before us (Schuhmann and Smith 1987). How might he handle the matter of perceptual experience's field-like character if he were to tackle it head on?

We can gain some clarity here by turning to the present. Some naïve realists have recognized and attempted to make sense of the boundedness of perceptual experience (Soteriou 2013; French 2018). Matthew Soteriou recommends thinking of its boudnedness analogously to Kant's forms of sensory intuition, to the extent that the former, like the latter (on Kant's view), are to be explained by appeal to our subjective constitution. Pursuing this thought further may lead to the conclusion that phenomenal character is determined by the nature of the perceptual relation, but not entirely in terms of its mind-transcendent relatum. The perceptual relation itself or the qualities of its other relatum the perceiving subject of experience - may thus partly determine what it is like to have perceptual experience (Logue 2012; Christy 2018), yet in a way that would not require Daubert to take back or weaken what he says about transparency. Only further research into Daubert's yet unpublished manuscripts will tell us just what resources he has to offer for addressing issues such as these. 


\section{References}

Allen, K. (2016). A Naïve Realist Theory of Color. Oxford: Oxford University Press.

Allen, K. (2009). "Being coloured and looking coloured." Canadian Journal of Philosophy 39(4), 647670.

Ali, R. (2018). "Does hallucinating involve perceiving?” Philosophical Studies 175(3), 601-627.

Beck, O. (2018). "Rethinking naïve realism.” Philosophical Studies (online first), DOI: 10.1007/s11098018-1030-x

Berendzen, J.C. (2014), "Disjunctivism and perceptual knowledge in Merleau-Ponty and McDowell." Res Philosophica 91(3), 261-268.

Blattner, W. (1999), 'Is Heidegger a representationalist?' Philosophical Topics 27(2), pp. 179-294.

Block, N. (2003). "Mental paint." Reflections and Replies: Essays on the Philosophy of Tyler Burge (pp. 165200). Martin Hahn \& B. Ramberg (eds.). Cambridge: MIT Press.

Brewer, B. (2011). Perception and its Objects. Oxford: Oxford University Press.

Byrne, A. (2001). "Intentionalism defended." The Philosophical Review. 110(2), 199-240.

Cairns, D. (1973). Guide for Translating Husserl. The Hague: Martinus Nijhoff.

Campbell, J. (2002). Reference and Consciousness, Oxford: Oxford University Press.

Campbell, J. (2009). "Consciousness and reference." The Oxford Handbook of Philosophy of Mind (648-

662). A. Beckermann, B. McLaughlin, and S. Walter (eds). Oxford: Oxford University Press.

Campbell, J. and Q. Cassam (2016). Berkeley's Puzzle. Oxford: Oxford University Press.

Christy, J. (2018). "Naïve realism: A simple view." Philosophical Studies, DOI: https://doi.org/10.1007/s11098-018-1120-9.

Conduct, M. (2008). "Naïve realism, adverbialism, and perceptual error." Acta Analytica 23, 147-159.

Dreyfus, H. (2002). "Intelligence without representation: Merleau-Ponty's critique of mental representation." Phenomenology and the Cognitive Sciences 1, 367-83.

Dretske, F. (1995). Naturalizing the Mind. Cambridge: MIT Press.

Drummond, J. (2008). Historical Dictionary of Husserl's Philosophy. Lanham, MD: Scarecrow Press.

Ducasse, C.J. (1942). "Moore's Refutation of Idealism." The Philosophy of G.E. Moore (223-252). P. Schilpp (ed.). Chicago: Northwestern University Press.

Fish, W. (2009). Perception, Hallucination, and Illusion. Oxford: Oxford University Press.

Frechette, G. (2013). "Searching for the self: Early phenomenological accounts of self-consciousness from Lotze to Scheler." International Journal of Philosophical Studies 21(5), 654-679.

French, C. (2018). "Naïve realism and diaphaneity." Proceedings of the Aristotelian Society, DOI: $10.1093 /$ arisoc/aoy006.

Genone, J. (2014). “Appearance and illusion.” Mind 123(490), 339-376.

Gert, J. (2006). "A realistic color realism.” Australasian Journal of Philosophy 84(4), 565-589.

Gurwitsch, A. (2010). The Field of Consciousness: Theme, Thematic Field, and Margin. The Collected Works of Aron Gurwitsch (1901-1973), Vol. III. Dordrecht: Springer.

Heidegger, M. (1985). History of the Concept of Time: Prolegomena. T. Kisiel (trans.). Bloomington: Indiana University Press.

Heidegger, M. (1962). Being and Time. J. Macquarrie and E. Robinson (trans.). New York: Harper Collins.

Hellie, B. (2007). "Factive Phenomenal Characters.” Philosophical Perspectives 21, pp. 259-306. 
Hopp, W. (2014). "Is seeing intentional? A response to Travis." Methodos 14, doi: $10.4000 /$ methodos.4108.

Hopp, W. (2011). Perception and Knowledge: A Phenomenological Account. Cambridge: Cambridge University Press.

Horgan, T. and J. Tienson (2002). "The intentionality of phenomenology and the phenomenology of intentionality." Philosophy of Mind: Classical and Contemporary Readings (520-533). D. Chalmers (ed.). Oxford: Oxford University Press.

Husserl, E. (2001a). Logical Investigations, Volume 2. J.N. Findlay (trans.), D. Moran (ed.). London: Routledge.

Husserl, E. (2001b). Analyses concerning Passive and Active Synthesis. A. Steinbock (ed.). Dordrecht: Kluwer.

Husserl, E. (1997). Thing and Space: Lectures of 1907. R. Rojcewicz (trans.). Dordrecht: Kluwer.

Husserl, E. (1982), Ideas Pertaining to a Pure Phenomenology and to a Phenomenological Philosophy, First Book. F. Kersten (Trans.). The Hague: Martinus Nijhoff Publishers.

Husserl, E. (1977), Phenomenological Psychology. Lectures, Summer Semester 1925. J. Scanlon (trans.). The Hague: Martinus Nijhoff.

Ingarden, R. (1975). On the Motives which led Husserl to Transcendental Idealism. A. Hannibarlsson (trans.). The Hague: Martinus Nijhoff.

Kalderon, M. (2011). "Color illusion.” Nous 45(4), 751-775.

Kennedy, M. (2009). "Heirs of Nothing: The Implications of Transparency." Philosophy and Phenomenological Research 79(3), 574-604.

Kriegel, U. (2002). "Phenomenal content." Erkenntnis 57, 175-198.

Kriegel, U. (2011). “The veil of abstracta." Philosophical Issues 21(1), pp. 245-267.

Langsam, H. (2016). "The intuitive case for naïve realism.” Philosophical Explorations 20(1), 106-122.

Levinas, E. (1998). Discovering Existence with Husserl. R. Cohen and M. Smith (trans.). Evanston, IL: Northwestern University Press.

Levinas, E. (1969). Totality and Infinity. A. Lingis (Trans.). Dordrecht: Kluwer.

Logue, H. (2012). “Why naïve realism?” Proceedings of the Aristotelian Society 112 (2.2), 211-237.

Lotz, C. (2007). "Cognitivism and practical intentionality: A critique of Dreyfus's critique of Husserl." International Philosophical Quarterly 47(2), pp. 153-166.

Martin, M.G.F. (2004). “The Limits of Self-Awareness.” Philosophical Studies 120(1-3), 37-89.

Martin, M.GF. (2002). “The Transparency of Experience." Mind and Language, 17, 376-425.

Masrour, F. (forthcoming). "On the possibility of hallucinations." Mind.

McDowell, J. (1994). "The Content of Perceptual Experience." Philosopbical Quarterly 44, 190-205.

McDowell, J. (1982). "Criteria, Defeasibilty, and Knowledge." Proceedings of the British Academy, 68: 455-79.

Merleau-Ponty, M. (2002). Phenomenology of Perception. C. Smith (Trans.). London: Routledge Classics.

Moran, A. (2018). "Naïve realism, seeing stars, and perceiving the past." Pacific Philosophical Quarterly. https://doi.org/10.1111/papq.12238.

Moran, D. (1999). "Our Germans are better than your Germans: Continental and analytic approaches to intentionality reconsidered." Philosophical Topics 27(2), 77-106.

Moran, D. (2013). "Intentionality: Some lessons from the history of the problem from Brentano to the present." International Journal of Philosophical Studies 21(3), pp. 317-358.

Mulligan, K. and B. Smith (1986). "A relational theory of the act." Topoi 5(2), 115-130. 
Noë, A. (2004). Action in Perception. Cambridge: MIT Press.

Overgaard, S. (2013). "Motivating disjunctivism." Husserl Studies 29(1), 51-63.

Preston, B. (1994). "Husserl's non-representational theory." Southern Journal of Philosophy 31, pp. 209232.

Romano, C. (2011). "Challenging the transcendental position: The holism of experience." Continental Philosophy Review 44(1), 1-21.

Romano, C. (2012). "Must phenomenology remain Cartesian?” Continental Philosophy Review 45(3), $425-445$.

Romano, C. (2015), At the Heart of Reason. C. Romano and M. Smith (trans.). Evanston, IL: Northwestern University Press.

Sartre, J. (1960). The Transcendence of the Ego. F. Williams and R. Kirkpatrick (trans.). New York: Hill and Wang.

Sartre, J.-P. (1956). Being and Nothingness. H. Barnes (Trans.). New York: Washington Square Press.

Schellenberg, S. (2011). "Perceptual Content Defended." Noús 45(4), 714-750.

Schellenberg, S. (2010). "The particularity and phenomenology of perceptual experience." Philosophical Studies 149(1), pp. 19-48

Schuhmann, K. (1989). "Husserl's concept of the noema: A Daubertian critique." Topoi 8(1), 53-61.

Schuhmann, K. and B. Smith (1985). “Against idealism: Johannes Daubert vs. Husserl's Ideas I." Review of Metaphysics 39, 763-793.

Schuhmann, K. and B. Smith (1987). "Questions: An essay in Daubertian phenomenology.” Philosophy and Phenomenological Research 47(3), 353-384.

Searle, J. (1983). Intentionality: An Essay in the Philosophy of Mind. Cambridge: Cambridge University Press.

Siegel, S. (2010). "Do Experiences Have Contents?" B. Nanay (ed.). Perceiving the World (333-68). New York: Oxford University Press.

Siegel, S. (2010). "Do experiences have contents?” Philosophical Review 115, 355-388.

Smid, R. (1985). "An early interpretation of Husserl's phenomenology: Johannes Daubert and the Logical Investigations." Husserl Studies 2(3), 267-290.

Smith, B. (1984). "Acta cum fundamentalis in re." Dialectica 38(2-3), 157-178.

Smith, B. (1997). "Realistic phenomenology." Encyclopedia of Phenomenology (586-590). L. Embree (ed.). Dordrecht: Kluwer.

Smith, A.D. (2008). "Husserl and externalism." Synthese 160(3), 313-333.

Smith, D.W. and R. McIntyre (1982). Husserl and Intentionality. Dordrecht: Kluwer.

Soteriou, M. (2016). Disjunctivism. New York: Routledge.

Soteriou, M. (2013). The Mind's Construction. Oxford: Oxford University Press.

Staiti, A. (2015). “On Husserl's alleged Cartesianism: A reply to Claude Romano." Husserl Studies $31(2), 123-141$.

Stazicker, J. (2018). "The visual presence of determinable properties." In Phenomenal Presence. F. Dorsch and F. Macpherson (eds.). Oxford: Oxford University Press.

Szanto, T. (2012). Bewusstsein, Intentionalität und nentale Repräsentation. Husserl und die analytische Philosophie des Geistes. Berlin: De Gruyter.

Travis, C. (2004). "The silence of the senses." Mind113(449), 57-94.

Travis, C. and E. Kalderon (2013). "Oxford realism." Oxford Handbook of the History of Analytic Philosophy (489-517). Michael Beaney (ed.). Oxford: Oxford University Press. 
Tye, M. (2000). Consciousness, Color, and Content. Cambridge, MA: MIT Press.

Tye, M. (2002). "Representationalism and the transparency of experience." Nous 36(1), 137-151. Wrathall, M. (1998). "Intentionality without representations." Philosophy Today 42, pp. 182-189.

Zahavi, D. (1994). "Intentionality and the Representative Theory of Perception." Man and World 27(1), 37-47. 